\title{
Ultrasound Assisted Extraction of Oil from Rice Bran: A Response Surface Methodology Approach
}

\author{
Krishnan VCA, Kuriakose $S$ and Rawson $A^{*}$
}

Department of Food Engineering and Design, IICPT, Thanjavur, Tamilnadu, India

\begin{abstract}
In the present study, ultrasound-assisted extraction of oil from rice bran was investigated through response surface methodology (RSM), where process variables were amplitude level (50-100\%) and sonication time (5-30 min). It was found that all process variables had significant $(p<0.05)$ effects on the response variable. A central composite design $(C C D)$ was used to determine the optimum process conditions. Optimal conditions were identified as $93 \%$ amplitude level and 26 min sonication time for maximum crude oil yield of $10.8 \%$. It was found that oil yield by ultrasound-assisted extraction using ethanol as solvent was higher than that of the conventional method using hexane or ethanol as solvent. Furthermore peroxide value and free fatty acid values were comparable in all the extracted samples. GC-MS analysis confirmed that ultrasound treated samples had a higher percentage of unsaturated fatty acids compared to conventional extraction using hexane. It was also observed that solvent extraction using ethanol showed higher percentage of the unsaturated fatty acid compared to hexane as solvent. This study confirms that ultrasound assisted extraction using ethanol as solvent can retain maximum unsaturated fatty acid compared to conventional hexane extracted sample, which is a food grade solvent. Hence in conclusion ultrasound assisted extraction has the potential to replace the conventional solvent extraction.
\end{abstract}

Keywords: Ultrasound; Extraction; Rice bran; Oil; RSM

\section{Introduction}

Rice (Oryza sativa) is the most important cereal crop cultivated around the world, which feeds more than half the world's population. Global rice production is expected to increase to a record 497 million tons in 2013-14, up about 1.3\% from around 491 million tons in 201213 , according to the FAO [1]. Agricultural by-products are often treated as waste materials and therefore their high nutraceutical content is underutilized. Hence in recent years special attention is being given to edible oil food supplement production from food processing byproducts.Rice Bran Oil (RBO) is unique edible oil produced from the outer brown layer of rice which is removed in the form of rice bran during the polishing process of the rice milling industry. Extraction of oil from rice bran is presently the most widespread and economically important process in recovering bran components. Most of the oil in the rice grain is located in the bran and germ, which usually contains about $15-22 \mathrm{wt} \%$ oil and are obtained during the milling process used to produce white rice. Most of the oils were produced by distillation and solvent extraction. In a case of solvent extraction, it is difficult to separate solvent from extracted oil and there is a risk of remaining solvent in oil though this method has the merit of getting large amount of oils. Hence if oil is extracted by using non- thermal techniques, there is no risk of solvent contamination, thermolability, and chemical deformation which occurs in solvent extraction or distillation of biomolecules. Furthermore, it is possible to increase an extraction efficiency of the total extracts and cut down costs by recycling the extraction solvent [2]. Many novel non-thermal processing technologies have been identified which have good potential to extract the valuable compound and oil present in rice bran. One such emerging non-thermal technology is power ultrasound. Power ultrasound has been recognized as a potential technology, alternative to conventional extraction method in the food industry. Until date no studies have been reported on ultrasound assisted extraction of oil from rice bran. Hence the objective of the study was to optimize and validate the extraction method using power ultrasound for higher yield of oil from rice bran using response surface methodology and compare ultrasound assisted RBO and solvent extracted method with respect to oil yield, and other quality attributes.

\section{Materials and Methods}

\section{Sample collection}

Rice bran of Alappuzha D1 brown rice variety a Kerala cultivar was collected from Nirapara rice mill industry, Kochi, Kerala. Rice bran was sieved using $500 \mu \mathrm{m}$ sieve and was stabilized at $110^{\circ} \mathrm{C}$ for $20 \mathrm{~min}$ to inactivate lipase enzyme according to method reported by [3]. Rice bran after stabilization was vacuum packed and kept in deep freezer at $-5^{\circ} \mathrm{C}$.

\section{Chemicals}

Analytical grade ethanol and n-hexane were used as solvent for extraction (Merck Specialities Private limited, Mumbai). Potassium hydroxide, Sodium thiosulphate, Glacial acetic acid, Chloroform, Phenolphthalein indicator, Starch solution were used for chemical analysis of oil and Dichloromethane, Sodium methoxide, Petroleum etherof chromatography or analytical grade was used for GC- MS analysis (Merck Specialities Private limited, Mumbai).

\section{Rotary evaporator}

Rotary evaporator was used for evaporating the solvent from the sample (Strike 102 model from Steroglass Private Limted, Italy) was used for the study. Rotary evaporator temperature was maintained at $50^{\circ} \mathrm{C}$ and speed was set at $250 \mathrm{rpm}$ which was selected by preliminary study.

\section{Ultrasonic probe type system}

Ultrasonic probe type system (VCX750 ultrasonic processor

*Corresonding author: Ashish Rawson, Department of Food Engineering and Design, IICPT, Thanjavur, Tamilnadu, India, E-mail: ashishrawson@gmail.com

Received April 01, 2015; Accepted May 01, 2015; Published May 08, 2015

Citation: Krishnan VCA, Kuriakose S, Rawson A (2015) Ultrasound Assisted Extraction of Oil from Rice Bran: A Response Surface Methodology Approach. J Food Process Technol 6: 454. doi:10.4172/2157-7110.1000454

Copyright: (c) 2015 Krishnan VCA, et al. This is an open-access article distributed under the terms of the Creative Commons Attribution License, which permits unrestricted use, distribution, and reproduction in any medium, provided the original author and source are credited. 
Sonics, New York, USA) was used for ultrasound treatment of the sample. The samples were treated for different amplitude level and time combination and maintain constant pulsation. The ultrasound probe of $19 \mathrm{~mm}$ diameter was attached to the ultrasound transducer which has a constant frequency of $20 \mathrm{kHz}$ and maximum amplitude of $58 \mu \mathrm{m}$. The amplitude level and time combination range was selected based on preliminary trial and optimized condition was obtained using Design Expert software.

\section{Variable of the analysis}

Extraction of rice bran oil was done by two methods.

1) Conventional solvent extraction method by using: a) nhexane, b) ethanol and

2) Ultrasound-assisted extraction using ethanol.

Process variables considered in the study were amplitude level (\%) and time (min) and the response variable was oil yield (\%).

\section{Conventional extraction}

The rice bran powder $(20 \mathrm{~g})$ was mixed with $\mathrm{n}$ - hexane in the ratio 1:6 ratio in a conical flask of $250 \mathrm{ml}$. The flask was put into the water bath with a controlled temperature at $40^{\circ} \mathrm{C}$ for $15 \mathrm{~min}$ and allowed to cool. After extraction the extracts were filtered through Whatman No.1 filter paper and then the solution was collected and concentrated with a rotary evaporator (Strike 102, steroglass Private Limited, Italy) to acquire the rice bran oil.

\section{Ultrasound assisted extraction}

Rice bran powder $(20 \mathrm{~g})$ was placed in a $250 \mathrm{~mL}$ beaker containing ethanol. The solid/solvent ratio was $1: 6(\mathrm{~g} / \mathrm{mL})$. The flask was placed in an ultrasonic probe type system(VCX750 ultrasonic processor Sonics, New York, USA). The ultrasound probe of $19 \mathrm{~mm}$ diameter was attached to the ultrasound transducer. A constant frequency of $20 \mathrm{kHz}$ was used for the treatment of samples. The samples were subjected to treatments with amplitude level of 50 to $100 \%$ and treatment time of 5 and $30 \mathrm{~min}$ with pulsation $5 \mathrm{~s}$ on and $5 \mathrm{~s}$ off. During the treatment time the rise in temperature was controlled by placing the sample containing beaker in an ice bath such that the overall temperature of the sample was maintained around $35^{\circ} \mathrm{C}$. The input range of the selected variables was determined by preliminary experiments. After extraction, the extracts were filtered through the Whatman No.1, Filter paper. Ethanol was removed from the extracts by evaporation under vacuum at $50^{\circ} \mathrm{C}$ using a rotary evaporator (Strike 102, Steroglass Private Limited, Italy). Subsequently, the weight of oil was calculated.

\section{Yield determination}

The yield of rice bran oil was calculated using the following formula:

$$
\text { Yield }(\%)=\frac{\text { Weight of flask with concentrated oil }- \text { Empty weight of flask }}{\text { Sample weight }}
$$

\section{Experimental design and Statistical analysis}

Response surface methodology (RSM) was applied to optimize the process variables including amplitude level (50-100\%) and sonication time (5-30 $\mathrm{min})$ to achieve the highest amount of crude oil from Rice bran. A central composite design (CCD) with axial points was used for designing the experimental data. This generated 21 treatments with five replications at the centre points to estimate the repeatability of the method. The design consisted of eight factorial points, eight axial points and five center points; blocks were assumed to have no impact on the nature and shape of the response surface. The following second-order polynomial model was fitted to the data:

$$
Y i=\beta_{0}+\beta_{1} X_{1}+\beta_{2} X_{2}+\beta_{11} X_{1}^{2}+\beta_{22} X_{2}^{2}+\beta_{12} X_{1} X_{2}
$$

Where, Yi is predicted response, $\beta_{0}$ is offset term, $\beta_{1}$ and $\beta_{2}$ are the regression coefficients for linear effect terms, $\beta_{11}$ and $\beta_{22}$ are quadratic effects and $\beta_{12}$ areinteraction effects. In this model, $X_{1}$ and $X_{2}$ represent amplitude level and sonication time, respectively. The significant terms $(p<0.05)$ in the model were found by analysis of variance (ANOVA) based on $p$-value. The three-dimensional response surface plot was generated for the graphical interpretation of the interaction effect of independent variables on the response. Numerical optimization was carried out to predict the exact optimum level of independent variables leading to the desirable response goal. The model adequacy was determined using model analysis, lack of fit test, coefficient of determination $\left(R^{2}\right)$ and adjusted $R^{2}$. Furthermore, experimental data were compared with predicted values (method validation) in order to verify the adequacy of final reduced model. The experimental design matrix, data analysis, regression coefficients, generation of 3D graph and numerical optimization procedure were created using Design Expert Version 9.0.2.0 software (Stat-Ease Inc., 2021 East Hennepin Ave., Suite 480 Minneapolis, MN 55413, USA).

\section{Physico-chemical analysis}

The peroxide value was determined according to the official method [4]. Rice bran moisture content was determined following the official method [5]. The fatty acid value was determined using (IUPAC, 1979) method [6]. Density of oil was also calculated.

\section{Peroxide value}

Peroxide value (PV) is the measure of the lipid oxidation in foods, it assess the primary oxidative changes in the system. $5 \mathrm{~g}$ sample was weighed into a $250 \mathrm{ml}$ stoppered conical flask and $30 \mathrm{ml}$ of acetic acid chloroform mixture was added to it. $0.5 \mathrm{ml}$ saturated potassium iodide solution was added with a mohr pipette to the solution obtained earlier. It was allowed to stand for $1 \mathrm{~min}$ in dark with occasional shaking and then $30 \mathrm{ml}$ of water was added to it. Following this titratation was carried out of the liberated iodine with $0.1 \mathrm{~N}$ sodium thiosulphate solution, while vigorous shaking until yellow colour is almost gone. Furthermore $0.5 \mathrm{ml}$ starch solution was added as indicator and the titratation was continued with the titrate shaken vigorously to release all $\mathrm{I}_{2}$ from $\mathrm{CHCL}_{3}$ layer until blue colour disappeared. (AOAC method 965.33).

Peroxide value expressed as milli equivalent of peroxide oxygen per $\mathrm{kg}$ sample $(\mathrm{meq} / \mathrm{kg})$

$$
\text { Peroxide value }=\frac{\text { Titre } \times N \times 100}{\text { Weight of the sample }}
$$

Where,

Titre $=\mathrm{ml}$ of sodium thiosulphate used

$\mathrm{N}=$ normality of sodium thiosulphate solution

\section{Free fatty acid}

The acid value is determined by directly titrating the oil in an alcoholic medium against standard potassium hydroxide solution. Accurately weighed appropriate amount of sample is taken in a $250 \mathrm{ml}$ conical flask and $20 \mathrm{ml}$ of freshly neutralized ethanol is added to it, furthermore about 2-3 drops of phenolphthalein indicator is added to 
the solution. The sample is titrated against $0.1 \mathrm{~N} \mathrm{KOH}$ solution shaking vigorously during the titration until pale pink colour is obtained.

$$
\text { Acid Value }=\frac{56.1 \times V \times N}{W}
$$

Where,

$\mathrm{V}=$ volume in $\mathrm{ml}$ of standard potassium hydroxide

$\mathrm{N}=$ Normality of the potassium hydroxide solution

$\mathrm{W}=$ weight in $\mathrm{g}$ of the sample

The acidity is frequently expressed as free fatty acid for which calculation shall be

$$
\text { Free fatty acid as oliec acid }=\frac{28.2 \times \mathrm{V} \times \mathrm{N}}{\mathrm{W}} \text { percent by weight }
$$

\section{Fatty acid profile using GC-MS analysis}

Fatty acids profile was analyzed by GC-MS according to method described by Kumar et al. [7]. GC Clarus 500 Perkin Elmer (Shelton, USA), equipped with a Mass detector Turbo mass gold-Perkin Elmer and a Elite-5MS (5\% Diphenyl/95\% Dimethyl poly siloxane), $(30 \times 0.25 \mathrm{~mm} \times 0.25 \mu \mathrm{m}$ df $) \mathrm{GC}$ column was used for the analysis. Oven temperature was programmed isothermally to $110^{\circ} \mathrm{C}$ and held for 2 min, then was raised at the rate of $10^{\circ} \mathrm{C} / \mathrm{min}$ to $200^{\circ} \mathrm{C}$ and then at the rate of $5^{\circ} \mathrm{C} / \mathrm{min}$ to $280^{\circ} \mathrm{C}$ and held at this temperature for $9 \mathrm{~min}$ and the injector temperature was set at $250^{\circ} \mathrm{C}$. Heliumwas used as a carrier gas which flowed at a rate of $1 \mathrm{~mL} / \mathrm{min}$. A $2 \mu \mathrm{L}$ aliquot of oil was injected into the column at a split ratio of 10:1. GC was runned for duration of $36 \mathrm{~min}$. The mass spectrometer was operated in the electron - impact ionization (EI) mode at $70 \mathrm{eV}$. Mass spectra were scanned in the range of $\mathrm{m} / \mathrm{z} 45-450$. Fatty acid components were identified by matching their recorded mass spectra with those from library data (NIST VersionYear 2005) which were provided by the software for GC- MS system. The inlet temperature and the source temperature of $200^{\circ} \mathrm{C}$ were used and solvent delay for 0-2 min. The MS run time was $30 \mathrm{~min}$. Standard methyl esters of fatty acids were used as authentic samples. The fatty acids determination was accomplished by comparing with standards and was quantified as percentages of the total methyl ester peak areas.

\section{Results and Discussion}

\section{Optimization of ultrasound-assisted extraction conditions and verification of the model}

The experimental design and the related experimental results are presented in Table 1. The crude yield ranged from 3.35 to $11.1 \%$ oil. A second-order polynomial model was rendered by multiple linear regression analysis of the experimental data. The regression coefficients and significant probabilities of linear, quadratic and interaction effects of process variables are shown in Table 2 . Probability values ( $p$-value) revealed that all linear, quadratic and interaction terms, had significant $(p<0.05)$ effects on the oil yield. Therefore, the final model was obtained as follows:

$$
\begin{aligned}
& \text { Yield }=+20.68600-0.48502 \times \mathrm{X}_{1}-0.49218 \times \mathrm{X}_{2}-2.12000 \times 10^{-3} \times \mathrm{X}_{1} \mathrm{X}_{2}+4.33800 \times 10^{-3} \\
& \times \mathrm{X}_{1}^{2}+0.022872 \times \mathrm{X}_{2}
\end{aligned}
$$

Where, $X_{1}, X_{2}$ represent amplitude level and sonication time, respectively. According to Table 2, the $p$-value of the final reduced

\begin{tabular}{|c|c|c|c|}
\hline & Factor 1 & Factor 2 & Response 1 \\
\hline Run & A:Amplitude & B:time & Yield \\
\hline & $\%$ & $\min$ & $\%$ \\
\hline 1 & 92.68 & 26.34 & 10.5 \\
\hline 2 & 100.00 & 17.50 & 10.2 \\
\hline 3 & 75.00 & 17.50 & 4.2 \\
\hline 4 & 75.00 & 30.00 & 9.8 \\
\hline 5 & 75.00 & 17.50 & 4.3 \\
\hline 6 & 75.00 & 17.50 & 4.2 \\
\hline 7 & 57.32 & 26.34 & 7.0 \\
\hline 8 & 50.00 & 17.50 & 4.0 \\
\hline 9 & 75.00 & 17.50 & 4.3 \\
\hline 10 & 57.32 & 26.34 & 6.7 \\
\hline 11 & 75.00 & 5.00 & 5.9 \\
\hline 12 & 50.00 & 17.50 & 3.9 \\
\hline 13 & 57.32 & 8.66 & 3.4 \\
\hline 14 & 92.68 & 8.66 & 8.5 \\
\hline 15 & 75.00 & 17.50 & 4.8 \\
\hline 16 & 92.68 & 26.34 & 11.1 \\
\hline 17 & 57.32 & 8.66 & 3.4 \\
\hline 18 & 75.00 & 30.00 & 9.6 \\
\hline 19 & 92.68 & 8.66 & 8.9 \\
\hline 20 & 100.00 & 17.50 & 10.3 \\
\hline 21 & 75.00 & 5.00 & 6.5 \\
\hline
\end{tabular}
model was less than 0.05 which revealed that model fitness was significant. Moreover, the lack of fit test was non-significant $(p>0.05)$, indicating that the model could adequately fit the experiment data
Table 1: Experimental design and results of response variable.

\begin{tabular}{|l|c|c|c|c|c|c|}
\hline & Sum of & & Mean & F & p-value & \\
\hline Source & Squares & df & Square & Value & Prob> F & \\
\hline Model & 150.53 & 5 & 30.11 & 482.22 & $<0.0001$ & significant \\
\hline A-Amplitude & 82.67 & 1 & 82.67 & 1324.11 & $<0.0001$ & \\
\hline B-time & 27.88 & 1 & 27.88 & 446.54 & $<0.0001$ & \\
\hline AB & 0.88 & 1 & 0.88 & 14.06 & 0.0019 & \\
\hline $\mathrm{A}^{\wedge} 2$ & 18.97 & 1 & 18.97 & 303.84 & $<0.0001$ & \\
\hline $\mathrm{B}^{\wedge} 2$ & 32.96 & 1 & 32.96 & 527.91 & $<0.0001$ & \\
\hline Residual & 0.94 & 15 & 0.062 & & & \\
\hline Lack of Fit & 0.15 & 3 & 0.05 & 0.77 & 0.5332 & notsignificant \\
\hline Pure Error & 0.79 & 12 & 0.065 & & & \\
\hline Cor Total & 151.47 & 20 & & & & \\
\hline
\end{tabular}

Table 2: Analysis of variance (ANOVA) and coefficients of the final regression equation.

(Table 2). It was observed that the predicted values were very close to the actual values, $R^{2}(0.993)$ confirming the true behavior of the system which was well defined by the regression model (Figure 1). In addition, the suitability of the rendered model was supported by the closeness of adjusted- $R^{2}(0.991)$ to 1 presenting a high degree of correlation between the experimental and predicted values. Table 3 shows the $R^{2}$ values and C. V. (\%), indicating model fitness was significant.A three dimensional response surface graph was plotted indicating the interaction effect of process variables (amplitude level and sonication time) on the response (yield) (Figure 2). It was found out that increase of amplitude level $\left(\mathrm{X}_{1}\right)$ resulted in increase of oil yield. Similar results were obtained for antioxidant compounds from marjoram [8] and melanin from auricular fruit bodies [9] during ultrasound assisted extraction. This may be due to the fact that higher amplitude of ultrasound may damage more cell walls releasing more crude oil to the solvent [10]. Furthermore ultrasound assisted extraction has been reported to increase oil extraction through the action of accelerating the rehydration or swelling of cells that is accompanied by the fragmentation of the tissue matrix [11]. This involves the mass transfer and penetration of the solvent into the cell promoting absorption of cell contents into the solvent [12]. In 


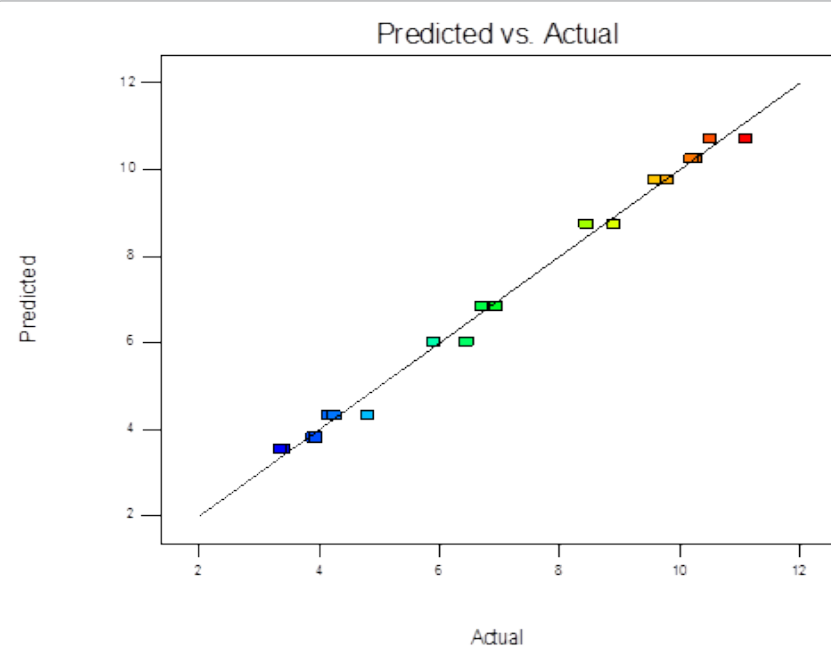

Figure 1: Plot of predicted crude extract yield related with experimental values.

\begin{tabular}{|c|c|c|c|}
\hline Std. Dev. & 0.25 & $R^{2}$ & 0.9938 \\
\hline Mean & 6.71 & $\operatorname{Adj}^{2}$ & 0.9918 \\
\hline C.V. \% & 3.72 & Pred $R^{2}$ & 0.9880 \\
\hline PRESS & 1.82 & Adeq Precision & 53.805 \\
\hline
\end{tabular}

Table 3: $R^{2}$ values and C. V. (\%) of the final model.

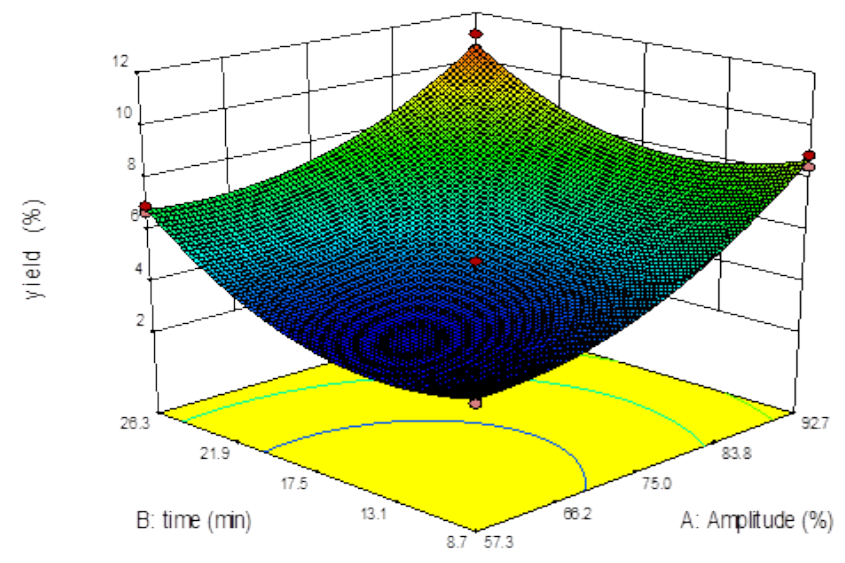

Figure 2: Response surface plots for yield as a function of: amplitude level $(\%)$ and sonication time $(\mathrm{min})$.

\section{Comparison of oil extraction by different methods}

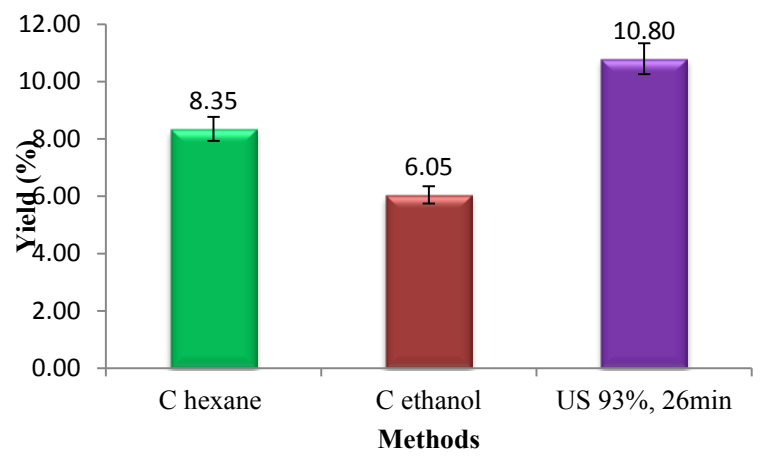

Figure 3: Comparison of oil extraction by different methods. this study, increasing the amplitude and the exposure time to sonication increased the oil yield from the rice bran. A numerical optimization was performed through desirability function method to determine the optimum level of process variables leading to maximum oil yield. The optimal conditions were determined as $93 \%$ amplitude level and 26 min sonication time. The re-checking experiment was performed in triplicate according to the optimal conditions in order to compare the predicted result with the practical value. The mean value of $10.8 \%$ oil obtained from real experiment which was very close to the predicted result ( $10.7 \%$ oil) indicating the validity and adequacy of response model to reflect the expected optimization.

\section{Comparison of oil extraction by different methods}

Rice bran oil was extracted by conventional extraction method using hexane, conventional extraction method using ethanol and ultrasound assisted extraction using ethanol. Conventional extraction method had $8.35 \%$ and $6.05 \%$ yield for hexane and ethanol, respectively (Figure 3). Whereas in case of optimized ultrasound assisted extraction sample had a yield of $10.80 \%$. The higher yield was achieved at $93 \%$ amplitude for $26 \mathrm{~min}$ of ultrasound treated sample. As mentioned earlier ultrasound treated sample gave higher yield, which has been studied earlier by various research groups and may be attributed to the formation of cavitation where the cavities expand and implode after just a few cycles (usually in microseconds) which is termed as transient cavitation. The physical effects of transient cavitation produce a hot spot in its immediate vicinity i.e., a zone of high temperature and high shear forces where free radicals are created in the matter of a few microseconds

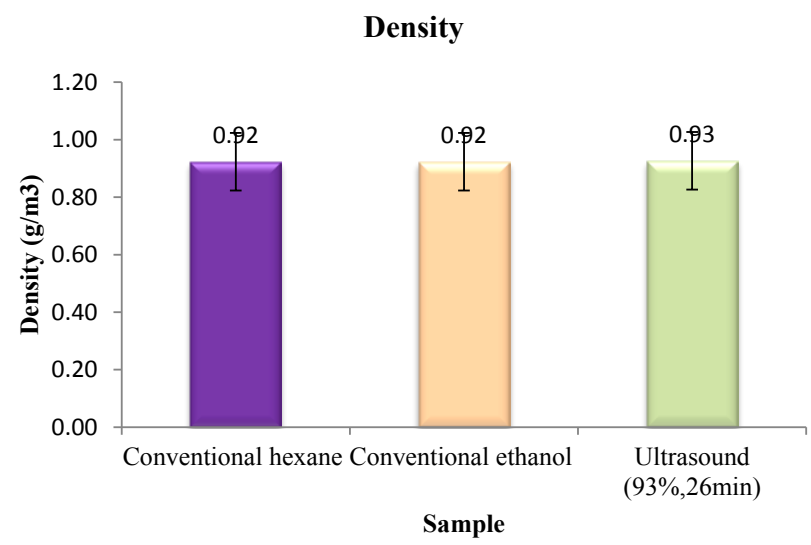

Figure 4: Density of conventional and ultrasound treated samples.

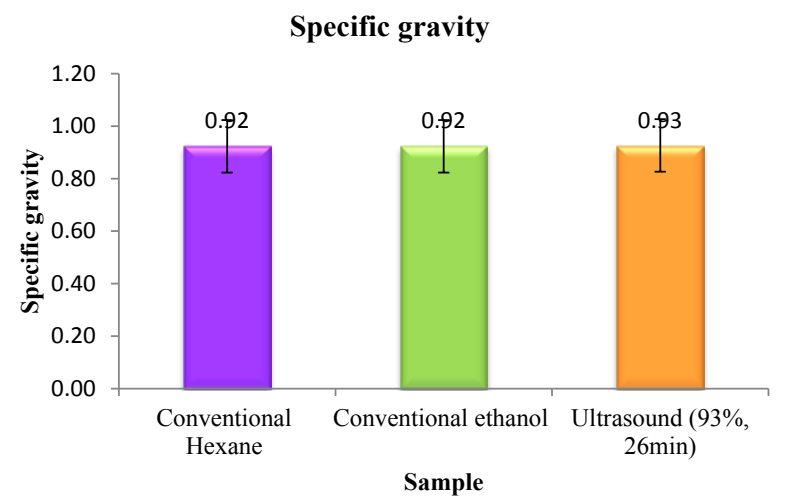

Figure 5: Specific gravity of conventional and ultrasound treated samples. 
[13-16]. The mechanical effects of cavitation immediately disrupt intact biological cells in these hot spots by rupturing biological membranes and cell walls. Consequently, cellular material pours out into the processing medium made up of the solvent, and lipids are selectively dissolved in it. This process forms the basis for Ultrasound-Assisted Extraction (UAE) and is responsible for the much higher oil yields from ultrasonic treatment in comparison to other methods [16,17].

\section{Density and specific gravity}

Density and specific gravity of conventional hexane extracted, conventional ethanol and ultrasound sample of optimized condition was calculated. It was found that there was no significant difference

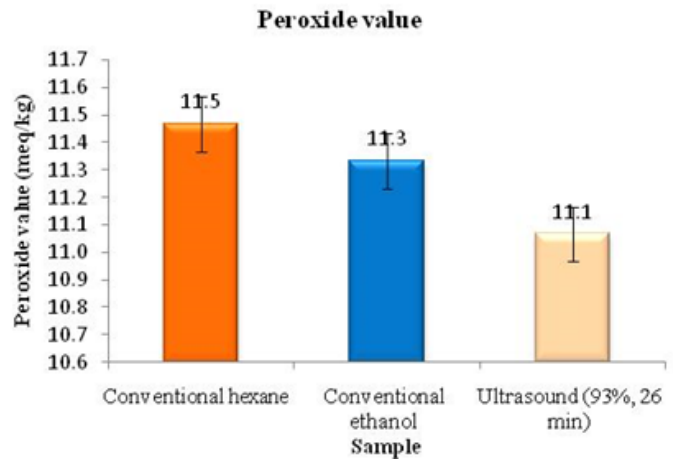

Figure 6: Peroxide value of conventional and ultrasound treated samples.

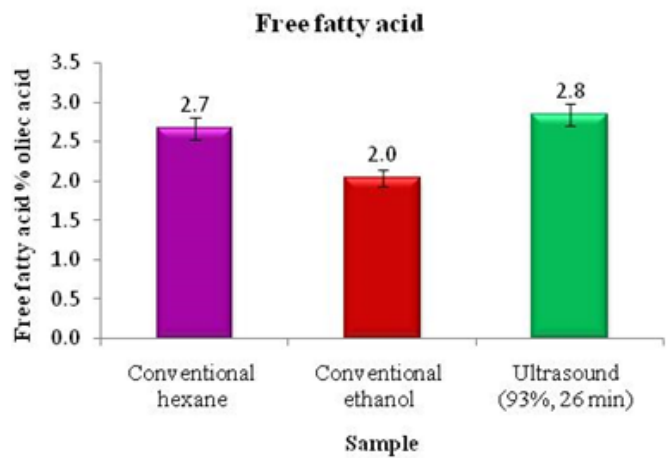

Figure 7: Free fatty acid of conventional and ultrasound treated samples. $(p>0.05)$ in density and specific gravity for three different extracted oil samples. Density and specific gravity were reported to be in similar range of $0.92-0.93 \mathrm{~g} / \mathrm{m}^{3}$. From the results it was clear that ultrasound treatment has no significant effect on density and specific gravity of oil, it is same as that of the conventionally extracted sample (Figures 4 and 5).

\section{Peroxide value}

There was no significant difference between the peroxide values of the crude oil obtained from extraction by hexane or ethanol or ultrasound assisted extraction with ethanol (Figure 6). The results shows that ultrasound assisted extracted rice bran oil was as good as conventionally extracted samples with respect to oxidative stability and hence it has good scope to replace the conventional solvent extraction using hexane.Similar results have been reported elsewhere for grape seed and papaya seed oil $[18,19]$.

\section{Free fatty acid}

The free fatty acid content is known as acid number/acid value. It increases during storage. The keeping quality of oil therefore relies upon the free fatty acid content. From (Figure 7) it is clear that ultrasound treated sample and conventional treated sample were comparable in free fatty acid content. Cavitation is the main cause of oxidation with ultrasound as micro bubbles form and collapse, resulting in areas of high temperature and pressure. Free radicals are formed during sonication which may result in increase of the FFA in ultrasound treated sample compared to conventional sample however since this happens so fast overall there is no change is free fatty acid as has been reported earlier by $[20,21]$. Fatty acid profile (GC-MS Analysis).

Fatty acid profile of the extract of crude rice bran oil was evaluated using GC-MS

Conventional Hexane GC-MS analysis: Gas-chromatography coupled with mass spectrometry was used to identify and measure the composition of fatty acids present in rice bran oil. Figure 8 illustrates the chromatogram of conventional extracted oil using hexane as solvent and (Table 4) presents the fatty acids composition of the analyzed rice bran oil. As it can be remarked from (Table 4), extracted rice bran oil have a high amount of $\omega-6$ polyunsaturated fatty acids (especially 9 , 12-Octadecadienoic acid (Z,Z)-fatty acid) i.e. linoleic acid. Linoleic acid is one of the fatty acid which is present in rice bran oil and it constitutes about $32-35 \%$ of oil. Linoleic acid is widely recognized as

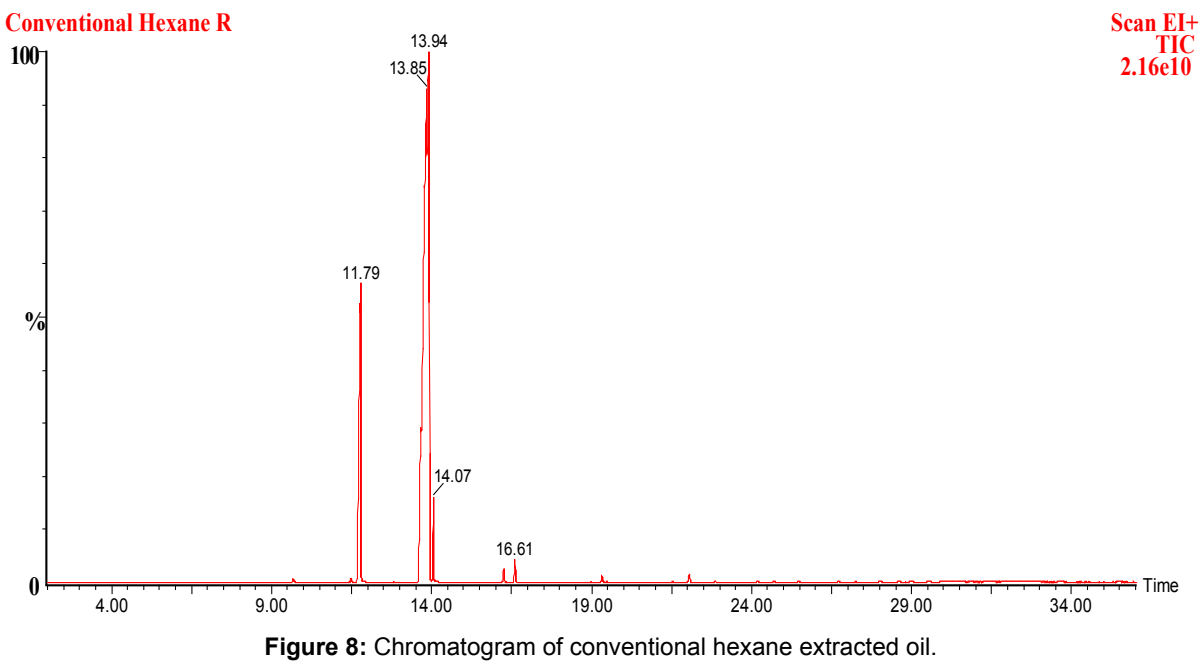


Citation: Krishnan VCA, Kuriakose S, Rawson A (2015) Ultrasound Assisted Extraction of Oil from Rice Bran: A Response Surface Methodology Approach. J Food Process Technol 6: 454. doi:10.4172/2157-7110.1000454

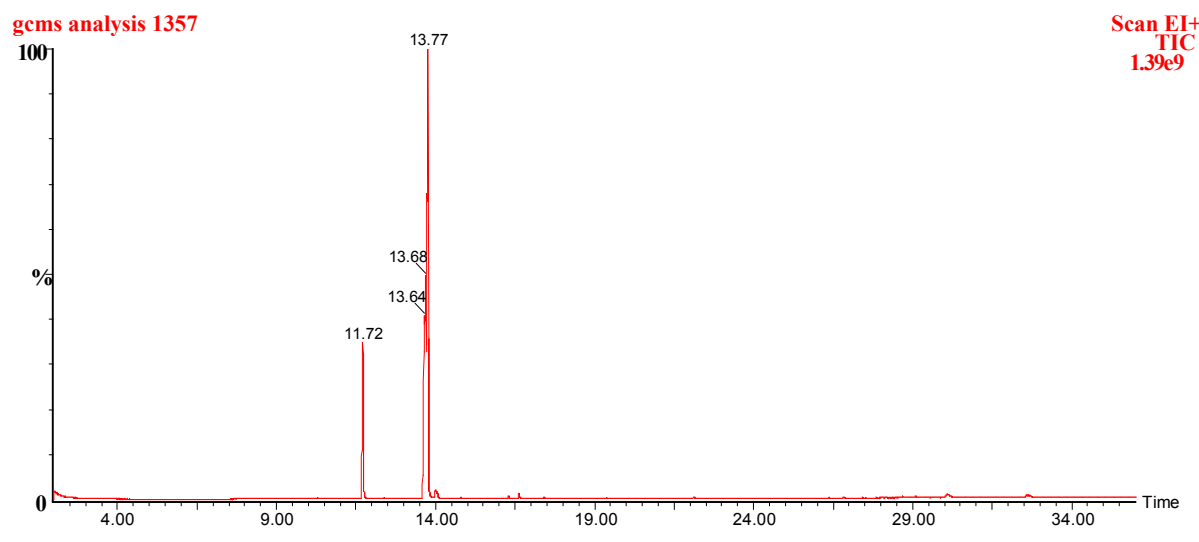

Figure 9: Chromatogram of ethanol extracted sample.

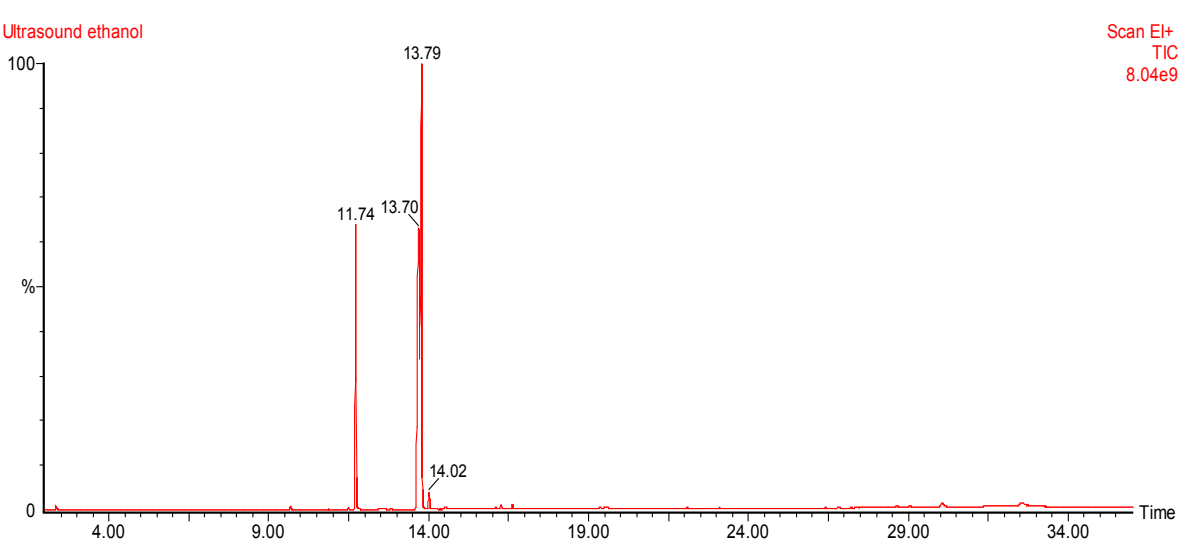

Figure 10: Chromatogram of ultrasound assisted extracted oil using ethanol as solvent

\begin{tabular}{|c|c|c|c|c|c|c|c|}
\hline No & RT & Name of the compound & $\begin{array}{l}\text { Molecular } \\
\text { Formula }\end{array}$ & MW & $\begin{array}{c}\text { Ethanol } \\
\text { Peak Area \% }\end{array}$ & $\begin{array}{l}\text { UAE- ethanol } \\
\text { Peak Area \% }\end{array}$ & $\begin{array}{c}\text { Hexane } \\
\text { Peak Area \% }\end{array}$ \\
\hline 1 & 9.67 & Octanoic acid, methyl ester & $\mathrm{C}_{9} \mathrm{H}_{18} \mathrm{O}_{2}$ & 158 & & 0.49 & 0.35 \\
\hline 2 & 10.72 & 9-Dodecenoic acid, methyl ester, (E)- & $\mathrm{C}_{13} \mathrm{H}_{24} \mathrm{O}_{2}$ & 212 & & 0.04 & 0.02 \\
\hline 3 & 11.49 & 7-Hexadecenoic acid, methyl ester, (Z)- & $\mathrm{C}_{17} \mathrm{H}_{32} \mathrm{O}_{2}$ & 268 & & & 0.23 \\
\hline 4 & 11.72 & Decanoic acid, methyl ester & $\mathrm{C}_{11} \mathrm{H}_{22} \mathrm{O}_{2}$ & 186 & 22.31 & 29.82 & 36.56 \\
\hline 5 & 13.77 & 9,12-Octadecadienoic acid (Z,Z)- & $\mathrm{C}_{18} \mathrm{H}_{32} \mathrm{O}_{2}$ & 280 & 74.53 & 64.19 & 55.45 \\
\hline 6 & 14.01 & Hexadecanoic acid, methyl ester & $\mathrm{C}_{17} \mathrm{H}_{34} \mathrm{O}_{2}$ & 270 & 2.43 & 2.00 & 3.89 \\
\hline 7 & 16.63 & Hexadecanoic acid, 15-methyl-, methyl ester & $\mathrm{C}_{18} \mathrm{H}_{36} \mathrm{O}_{2}$ & 284 & 0.72 & & 1.47 \\
\hline 8 & 16.26 & $\begin{array}{c}\text { Cyclopropanepentanoic acid, 2-undecyl-, methyl } \\
\text { ester, trans- }\end{array}$ & $\mathrm{C}_{20} \mathrm{H}_{38} \mathrm{O}_{2}$ & 310 & & 0.67 & 0.88 \\
\hline 9 & 19.33 & Heptacosanoic acid, methyl ester & $\mathrm{C}_{28} \mathrm{H}_{56} \mathrm{O}_{2}$ & 424 & & 1.54 & 0.44 \\
\hline 10 & 22.06 & Triacontanoic acid, methyl ester & $\mathrm{C}_{31} \mathrm{H}_{62} \mathrm{O}_{2}$ & 466 & & 0.71 & 0.71 \\
\hline
\end{tabular}

Table 4: Components identified in the ethanol, n-hexane and ultrasound ethanol-Fatty Acid Profile.

an essential fatty acid which decreases the blood cholesterol, and hence reduces the risk of atherosclerosis and other health effects [22]. Linoleic acid has shown highest peak area of $55.45 \%$ at a retention time of 13.94 min. The saturated fatty acid detected in the extracts were Decanoic acid (36.56\%) and Hexadecanoic acid (3.89\%).

Conventional ethanol GC-MS analysis: GC-MS result of oil extracted by conventional extraction using ethanol as solvent is illustrated in Figure 9 and Table 4, presents the fatty acids composition of the analyzed rice bran oil. As it is shown in Table 4, extracted oil have a very high amount of $\omega-6$ polyunsaturated fatty acids (especially
9, 12-Octadecadienoic acid (Z, Z)-fatty acid) i.e. linoleic acid which has shown highest peak area of $74.53 \%$ at a retention time of $13.77 \mathrm{~min}$. A relatively lower content of saturated fatty acid was detected in the oil were Decanoic acid (22.31\%), Hexadecanoic acid (2.43\%). The result shows that ethanol extracted sample extracts higher amount of linoleic acid compared to hexane extracted sample.

Ultrasound assisted extraction using ethanol GC-MS analysis: GC-MS result of rice bran oil extracted by ultrasound assisted extraction using ethanol as solvent is illustrated in Figure 10 and Table 4 presents the fatty acids composition of the analyzed rice bran oil. As it is shown 
in Table 4. Extracted oil have a very high amount of $\omega-6$ polyunsaturated fatty acids (especially 9,12-Octadecadienoic acid (Z,Z)-fatty acid, (Figure 10) i.e. linoleic acid which has shown highest peak area of $64.19 \%$ at a retention time of $13.79 \mathrm{~min}$. The other fatty acid present in the oil were Decanoic acid (29.82\%) (Figure 10), Hexadecanoic acid (2.0\%). The results show that ultrasound sample has higher amount of linoleic acid compared to hexane extracted sample. It also shows higher amount of other saturated fatty acid compared to conventional hexane extracted sample. GC-MS analysis confirmed the peak identification of fatty acid methyl esters after the various extraction techniques, confirming fatty acid quantitation by gas chromatography. Results of the GC-MS analysis of ultrasound assisted and conventional extraction using ethanol shows a small decrease in the percentage of unsaturated fatty acids and an increase in the percentage of saturated fatty acids. It was observed that both the extracts were very rich in unsaturated fatty acids. The major unsaturated fatty acids which detected in extracts obtained using the conventional method and ultrasound were linoleic acid $(74.53 \%$ and $64.19 \%$ of total fatty acids, respectively). This is used as an indicator of the extent of fat deterioration because unsaturated fatty acids are more susceptible to oxidation, whereas saturated fatty acids are more stable to oxidation. The ultrasound assisted ethanol extracted oil sample has a higher percentage of unsaturated fatty acid and saturated fatty acid when compared to conventional extraction using hexane. This implies that ultrasound extraction using ethanol as solvent cause less oxidation and can retain maximum fatty acid compared to hexane extracted sample. Results indicate that oxidation of rice bran oil does occur upon application of ultrasound, however the difference in the GC-MS analysis between the sonicated and the conventional extraction using ethanol was small suggesting that sonication did not noticeably influence composition of the extracted oil.

\section{Conclusion}

The oil qualities like peroxide value, free fatty acid, density and specific gravity may not be affected by ultrasound as pre-treatment. Response surface methodology is a useful tool for predicting the optimized conditions with very low error. Hexane a toxic solvent can be replaced by food grade solvent such as ethanol. The ultrasound treatment reduces the extraction time, energy and risk of solvent contamination and solvent waste. The ultrasound sample may enhance the mass transfer leading to increased oil yield and higher $₫-6$ fatty acid i.e. Linoleic acid which is recognized as an essential fatty acid. The ultrasound-assisted extraction using ethanol as solvent is an effective and indeed feasible method for the extraction of crude oil rich in valuable compounds from rice bran.

\section{References}

1. http://faostat.fao.org/site/339/default.aspx

2. Huang WW, Wang W, Li J, Li Z (2013) Study on the Preparation Process of Rice Bran Oil by the Ultrasonic Enzymatic Extraction. Advance Journal of Food Science and Technology 5: 213-216.

3. Juliano BO, Bechtel DB (1985) The rice grain and its gross composition. The American Association of Cereal Chemists, St Paul, Minnesota, USA.

4. AOAC (2006) Official methods of analysis. Washington: Association of Official Analytical Chemists.

5. ASAE Standards (2003) Moisture measurement-unground grain and seeds. S352.2. ASAE. St Joseph, Mich, USA
6. IUPAC (1979) Standard Methods for the Analysis of Oils Fats and Derivatives Pergamon Press, New York, USA.

7. Kumar PP, Kumaravel S, Lalitha C (2010) Screening of antioxidant activity, total phenolics and GC-MS study of Vitex negundo. African Journal of Biochemistry Research 4: 191-195.

8. Hossain MB, Brunton NP, Patras A, Tiwari B, Donnell CP, et al. (2012) Optimization of ultrasound assisted extraction of antioxidant compounds from marjoram (Origanummajorana L.) using response surface methodology. Ultrasonics Sonochemistry 19: 582-590.

9. Zou Y, Xie C, Gongjian F, Gu Z, Han Y (2010) Optimization of ultrasoundassisted extraction of melanin from Auricularia auricular fruit bodies. Innovative Food Science and Emerging Technology 11: 611-615.

10. Patist A, Bates D (2008) Ultrasonic innovations in the food industry: From the laboratory to commercial production. Innovative Food Science and Emerging Technologies 9: 147-154

11. Toma M, Vinatoru M, Panikwnyk L, Mason TJ (2007) Ivestigation of the effects of ultrasound on vegetal tissues during solvent extraction. Ultrasonics Sonochemistry 8: 137-142.

12. Vinatoru M, Toma M, RaduO, Filip PI, Lazurca D, et al. (1997) The use of ultrasound for the extraction of bioactive principles from plant materials. Ultrasonics Sonochemistry 4: 135-139.

13. Suslick KS (1990) Sonochemistry. Science 247: 1439-1445.

14. Condon S, Raso J (2005) Microbial inactivation by ultrasound. Novel food processing technologies. CRC Press, USA.

15. Feng H, Yang W (2008) Power Ultrasound. Food Science and Technology International 14: 433-436.

16. Latheef BM (2012) Pulsed ultrasound-assisted solvent extraction of oil from soybeans and microalgae. Thesis, Department of Bioresource Engineering, McGill University, Montreal, Canada.

17. Wang L, Weller CL (2006) Recent advances in extraction of nutraceuticals from plants. Trends in Food Science and Technology 17: 300-312.

18. Da Porto C, Porretto E, Decorti D (2013) Comparison of Ultrasound assisted extraction with conventional extraction methods of oil and polyphenols from grape (Vitisvinifera L.) seeds. Ultrasonics Sonochemistry 20: 1076-1080

19. Samaram S, Mirhosseini H, Tana CP, MohdGhazali H (2014) Ultrasoundassisted extraction and solvent extraction of papaya seed oil: Crystallization and thermal behavior, saturation degree, color and oxidative stability. Industrial Crops and Products 52: 702-708.

20. Juliano P, Swiergon P, Lee KH, Gee PT, Clarke PT, et al. (2013) Effects of Pilot Plant-Scale Ultrasound on Plam Oil Separation and oil Quality. Journal of American Oil Chemical Society 90: 1253-1260.

21. Samaram S, Mirhosseini H, Tan CP, Ghazali HM (2013) Ultrasound-Assisted Extraction (UAE) and Solvent Extraction of Papaya Seed Oil: Yield, Fatty Acid Composition and Triacylglycerol Profile. Molecules 18: 12474-12487.

22. Orthoefer FT (1996) Rice bran oil: Healthy lipid source. Food Technology 50 $62-64$. 